Estudos Teológicos foi licenciado com uma Licença Creative Commons Atribuição - NãoComercial - SemDerivados 3.0 Não Adaptada

http://dx.doi.org/10.22351/et.v.57i2.2774

\title{
Mestrado Profissional em Teologia da Faculdades EST: PANORAMA HISTÓRICO E ATUAÇão PROFISSIONAL DE EGRESSOS E EGRESSAS ${ }^{1}$
}

\author{
Master's degree in Theology of Faculdades EST: \\ historical panorama and professional performance of graduates
}

\section{Gisela I. W. Streck ${ }^{2}$ Thiago Almeida Silveira ${ }^{3}$}

\begin{abstract}
Resumo: O artigo traz os resultados da pesquisa realizada junto ao Mestrado Profissional em Teologia da Faculdades EST e teve como objetivo verificar quais foram as mudanças e as transformações da realidade que a conclusão do curso de pós-graduação trouxe para os contextos profissionais onde atuam egressos e egressas. Apresenta um panorama histórico sobre o início e o crescimento do Mestrado Profissional em Teologia na Faculdades EST a partir de uma pesquisa documental, assim como um levantamento e análise dos assuntos pesquisados nos trabalhos finais de mestrandos e mestrandas durante o período de 2003 a 2013. Também foi realizada uma pesquisa social com egressos e egressas com o objetivo de analisar se houve mudanças significativas nos contextos em que atuam profissionalmente. Palavras-chave: Mestrado Profissional. Teologia. Impacto social. Egressos e egressas.
\end{abstract}

Abstract: The article presents the results of a research done into the Professional Masters in Theology at Faculdades EST that aimed to determine what were the changes and transformations in the reality that the conclusion of the postgraduate course brought to the professional contexts in which the graduates are working. Presents a historical overview of the beginning and growth of the Professional Masters in Theology in EST Colleges from a documentary research, as well as a survey and analysis of the issues surveyed in the late works of Masters Students during the period 2003 to 2013. Also a social survey was conducted with graduates in order to analyze whether there were significant changes in the contexts in which they work professionally.

Keywords: Professional Master. Theology. Social impact. Graduates.

1 O artigo foi recebido em 07 de junho de 2016 e aprovado em 12 de setembro de 2017 com base nas avaliações dos pareceristas ad hoc.

2 Doutora em Teologia pela Faculdades EST. Professora de Teologia, área de concentração Religião e Educação da Faculdades EST em São Leopoldo/RS, Brasil. É coordenadora do Mestrado Profissional da Faculdades EST. Contato: giselastreck@gmail.com

3 Foi bolsista de Iniciação Científica no projeto de pesquisa em 2014 e atualmente é bolsista de mestrado do CNPq e mestrando em Teologia na Faculdades EST, em São Leopoldo/RS, Brasil. Contato: talmeidasilveira@bol.com.br 


\section{Introdução}

O Mestrado Profissional no Brasil está regulamentado pela Portaria Normativa $n^{0} 17$, de 28 de dezembro de 2009, e publicada no Diário Oficial da União em 29 de dezembro de 2009. Nessa Portaria podem ser encontrados os objetivos do curso:

I - capacitar profissionais qualificados para o exercício da prática profissional avançada e transformadora de procedimentos, visando atender demandas sociais, organizacionais ou profissionais e do mercado de trabalho;

II - transferir conhecimento para a sociedade, atendendo demandas específicas e de arranjos produtivos com vistas ao desenvolvimento nacional, regional ou local;

III - promover a articulação integrada da formação profissional com entidades demandantes de naturezas diversas, visando melhorar a eficácia e a eficiência das organizações públicas e privadas por meio da solução de problemas e geração e aplicação de processos de inovação apropriados;

IV - contribuir para agregar competitividade e aumentar a produtividade em empresas, organizações públicas e privadas.

Parágrafo único. No caso da área da saúde, qualificam-se para o oferecimento do mestrado profissional os programas de residência médica ou multiprofissional devidamente credenciados e que atendam aos requisitos estabelecidos em edital específico. ${ }^{4}$

Na Portaria cabe destacar o foco na capacitação profissional avançada que visa a uma atuação transformadora para atender as necessidades da sociedade, nos seus diferentes contextos e especificidades. $\mathrm{O}$ enfoque pode ser definido a partir de três questões fundamentais: profissionais qualificados/as, prática profissional avançada e transformadora e demandas sociais.

No site da Fundação Coordenação de Aperfeiçoamento de Pessoal de Nível Superior - CAPES encontra-se um texto que explica o que é um Mestrado Profissional: “[...] é uma modalidade de Pós-Graduação stricto sensu voltada para a capacitação de profissionais, nas diversas áreas do conhecimento [...]”. E novamente são citadas as demandas que a sociedade apresenta e as exigências do mercado de trabalho. Sendo assim, o Mestrado Profissional, na sua organização, deve "apresentar uma estrutura curricular que enfatize a articulação entre conhecimento atualizado, domínio da metodologia pertinente e aplicação orientada para o campo de atuação profissional específico". Além disso, também a finalização do curso, por meio da apresentação de um trabalho final, deve atender a este objetivo de buscar subsídios para a transformação social através de uma atuação profissional inovadora e atenta aos diferentes problemas e situações que se apresentam. Ou seja, o "trabalho final do curso deve ser sempre vinculado a problemas reais da área de atuação do profissional-aluno [...]"5.

4 PORTARIA Normativa $n^{0}$ 17, de 28 de dezembro de 2009. Disponível em: <www.capes.org.br>. Acesso em: 12 abr. 2016.

5 Disponível em: <http://www.capes.gov.br/avaliacao/sobre-a-avaliacao/mestrado-profissional-o-que-e >. Acesso em: 11 abr. 2016 
O projeto de pesquisa Mestrado Profissional em Teologia da Faculdades EST: sua trajetória e suas contribuições em termos de impacto social ${ }^{6}$ teve como objetivo verificar quais foram as mudanças que podem ser verificadas nos contextos de atuação profissional de seus egressos e egressas. Para tanto, em termos metodológicos, realizou-se uma pesquisa documental nos resumos dos 287 trabalhos finais apresentados e defendidos até o ano de 2013, para a averiguação dos assuntos pesquisados pelos mestrandos e mestrandas; e uma pesquisa social através de questionário enviado por meio eletrônico para 378 egressos e egressas que finalizaram o curso até 2015. Além disso, a partir de pesquisa documental, foi feito um levantamento de dados para traçar um panorama histórico do Mestrado Profissional da Faculdades EST.

\section{O Mestrado Profissional em Teologia da Faculdades EST}

O Mestrado Profissional iniciou com a linha de pesquisa em liturgia, em janeiro de 2001 e teve duas edições. Em julho de 2005, uma nova linha de pesquisa iniciou suas atividades: educação comunitária com infância e juventude. Essa nova linha foi organizada pelo corpo docente do então Departamento de Educação e Religião (DEPED), e teve como parceiros de diálogo o Departamento de Catequese e o Departamento Nacional para Assuntos da Juventude (DNAJ), ambos da Igreja Evangélica de Confissão Luterana no Brasil (IECLB).

No dia 8 de junho de 2005, a Comissão de Pós-Graduação do então Instituto Ecumênico de Pós-graduação (IEPG) homologou o nome de 37 candidatos e candidatas para ingresso na linha de pesquisa "educação comunitária com infância e juventude", que obtiveram a aprovação no exame de seleção efetuado nos dias 26 e 27 de maio. A procedência dos candidatos era bastante diversificada, com pessoas vindas tanto de regiões mais distantes, como dos estados da Rondônia, Bahia, Minas Gerais, Paraná, Santa Catarina e Goiás, como da região metropolitana da Grande Porto Alegre. Em termos de formação, ingressaram pessoas das áreas da psicologia, pedagogia, teologia e filosofia, entre outras. No dia 04 de julho de 2005, iniciaram-se as atividades do primeiro módulo do curso na Faculdades EST, em São Leopoldo/RS, com 34 discentes matriculados. O encerramento dessa etapa foi no dia 04 de agosto de 2005.

Outras linhas foram criadas a partir de 2008, como ética e gestão, aconselhamento pastoral, práticas sociais e cuidado, ensino e leitura da Bíblia, HIV/AIDS e teologia, dimensões do cuidado. A média de matrículas por ano tem ficado em torno de 150 mestrandos e mestrandas, distribuídas nas diferentes linhas de pesquisa do Mestrado Profissional. Esse número tem se mantido nos últimos anos e mostra que o Mestrado Profissional pode ser considerado um programa consolidado, tendo já um

6 O referido projeto de pesquisa foi aprovado pelo Conselho de Pesquisa da Faculdades EST e teve vigência de 2014 a 2016. 
percurso que pode ser investigado, como forma de resgatar sua história e mostrar sua evolução e suas contribuições. ${ }^{7}$

Uma questão importante é verificar quais foram as mudanças que o Mestrado Profissional trouxe para a atuação profissional de seus egressos e egressas de acordo com as percepções deles e delas. São 378 mestres e mestras titulados até 2015. Atualmente não há um acompanhamento sistemático para averiguar quais são as mudanças e transformações que esses egressos e egressas percebem na sua atuação profissional após o término de seu curso.

No caderno de apresentação do Mestrado Profissional diz que o "Mestrado Profissional em Teologia destina-se a portadores de diploma superior em Teologia e áreas afins, que pretendam se qualificar neste campo profissional". Traz como objetivo geral: “Qualificar graduados em Teologia e áreas afins, aprimorando seus saberes e conhecimentos sobre áreas específicas, planejamento, elaboração, desenvolvimento, gestão, assessoramento, difusão, acompanhamento e/ou avaliação de ações, programas e projetos sociais, no campo educacional e litúrgico, como forma de atender a especificidade das Áreas de Concentração do Programa".

E como objetivos específicos: a) "Qualificar e aperfeiçoar profissionais na perspectiva da educação continuada nas áreas"; b) "Formar profissionais pós-graduados aptos para atuar na elaboração de novos conhecimentos e processos no campo eclesial de formação continuada na fé"; c) "Qualificar e habilitar profissionais a atuar como multiplicadores e agentes de educação comunitária que atuem em elaboração, gestão e avaliação de programas e projetos".

O perfil dos egressos e das egressas está definido da seguinte forma: "Nessa perspectiva, os/as profissionais titulados pelo Curso poderão atuar profissionalmente em Igrejas, bem como realizar trabalho autônomo e/ou em instituições do setor privado, como empresas, escritórios de planejamento e assessoria; do setor público, como ministérios, secretarias, empresas estatais; e do terceiro setor, como organizações não-governamentais (ONG’s), organizações da sociedade civil de interesse público (OSCIP's), outras organizações filantrópicas e fundações"».

O Mestrado Profissional da Faculdades EST tem conseguido dar conta dos objetivos a que se propõe? É possível verificar, a partir de sua história e sua evolução, se esse é um programa de pós-graduação que traz mudanças no contexto no qual estão inseridos e atuam profissionalmente seus egressos e suas egressas? Como o Mestrado Profissional tem contribuído para as mudanças e as transformações necessárias em contextos eclesiais, educativos e outros? Para buscar respostas a essas questões, foram realizadas duas pesquisas: a pesquisa social com egressos e egressas de 2003 a 2015 e a pesquisa documental nos resumos dos trabalhos finais de 2003 a 2013.

7 Essas informações estão disponíveis nas atas do Conselho de Pós-Graduação e Pesquisa da Faculdades EST.

8 MESTRADO Profissional em Teologia. Documentação acadêmica. Guia Acadêmico. Disponível em: $<$ http://www.est.edu.br/pos-graduacao/mestrado-profissional/documentacao-academica $>$. Acesso em: 11 abr. 2016 . 


\section{Pesquisa nos resumos dos trabalhos finais}

Num primeiro momento, foi feito um levantamento nos resumos dos trabalhos finais finalizados até 2013. Ao todo foram analisados 287 resumos e as respectivas palavras-chave. Os trabalhos finais examinados encontram-se disponíveis no acervo da biblioteca da Faculdades EST e estão digitalizados no catálogo on-line da biblioteca. A sistematização dos dados foi realizada por meio de análise de conteúdo. Para tanto, foi feita uma leitura preliminar de todos os dados coletados para estabelecer categorias de análise (p. ex. educação, espiritualidade, ética e moral) e uma catalogação dos temas de acordo com as linhas de pesquisa oferecidas no Mestrado Profissional durante o período pesquisado. A partir do estabelecimento das categorias, foi feita a sistematização dos dados, e sua análise também recebeu tratamento estatístico como forma de melhor visualizar os diferentes assuntos e os que receberam maior incidência. ${ }^{9}$ Deve-se observar que os assuntos dos trabalhos finais, muitas vezes, se enquadraram em mais de uma categoria de análise. ${ }^{10}$

Os 287 trabalhos finais analisados entre 2003 e 2013 estão divididos em sete linhas de pesquisa. No gráfico a seguir, está o número de trabalhos finais por linhas de pesquisa:

Gráfico $n^{\circ} 1$ - Número de trabalhos finais por linha de pesquisa

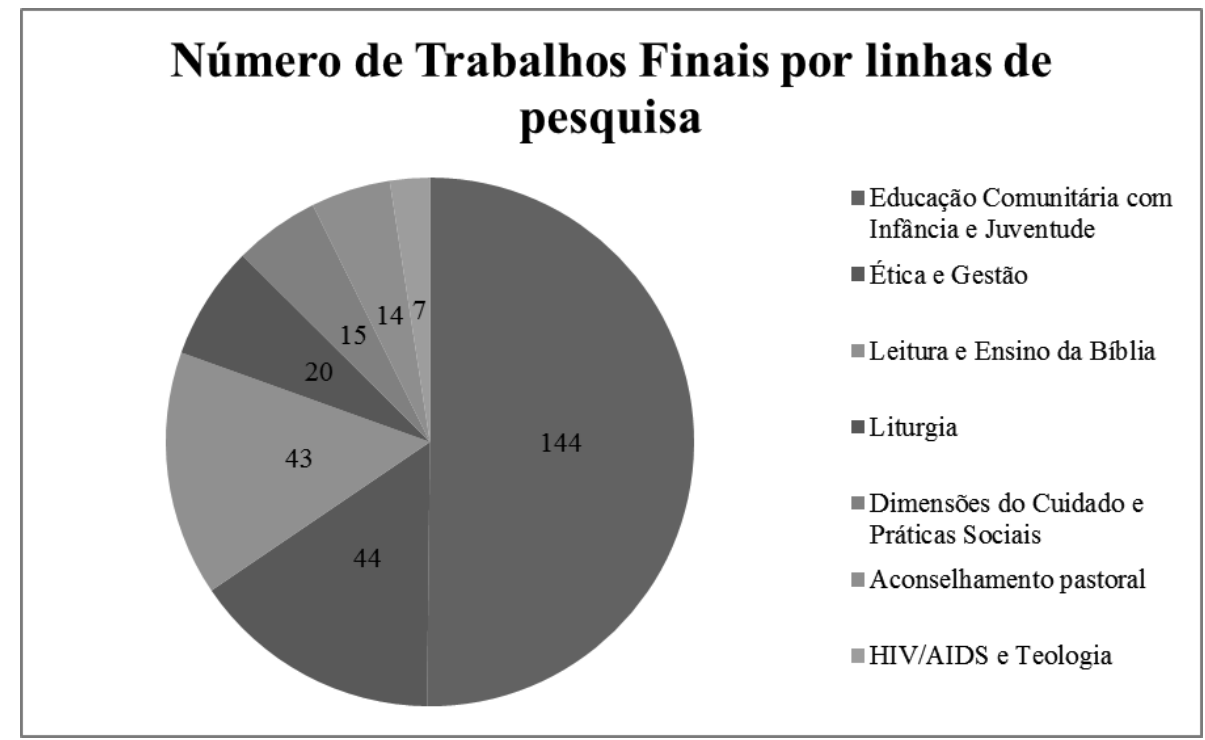

9 BARDIN, Laurence. Análise de Conteúdo. Lisboa: Edições 70, 2002.

${ }^{10}$ Por exemplo, o trabalho final "Liturgia e negritude: uma aproximação ao tema na perspectiva da Igreja Presbiteriana Unida do Brasil”, São Leopoldo, 2003, na linha de pesquisa em liturgia (2003), de Izaura Márcia Venerano, foi categorizado em dois assuntos: liturgia reformada e negritude. 
Em relação à disparidade em termos de produção por linha de pesquisa, é necessário considerar que liturgia foi a primeira linha de pesquisa, mas a partir de 2005 não foi mais oferecida; assim também as linhas de pesquisa de aconselhamento pastoral e HIV e teologia. As linhas de ética e gestão e de ensino e leitura da Bíblia iniciaram em 2009 e continuam sendo oferecidas, assim como dimensões do cuidado e práticas sociais, que iniciou em 2008.

O maior número de trabalhos finais na linha de pesquisa de educação comunitária com infância e juventude deve-se ao fato de essa linha estar sendo oferecida desde 2005, estando em 2017 na sua $12^{\mathrm{a}}$ edição.

No tocante ao número de trabalhos finais e as respectivas linhas de pesquisa, por ano ${ }^{11}$, são estes os números:

Tabela $\mathrm{n}^{\mathrm{O}} 1$ - Número de trabalhos finais e as respectivas linhas de pesquisa

\begin{tabular}{|c|c|c|c|c|c|c|c|c|c|c|c|}
\hline & 2003 & 2004 & 2005 & 2006 & 2007 & 2008 & 2009 & 2010 & 2011 & 2012 & 2013 \\
\hline $\begin{array}{c}\text { Educação } \\
\text { Comunitária } \\
\text { com Infância e } \\
\text { Juventude }\end{array}$ & -- & -- & -- & 1 & 21 & 9 & 30 & 19 & 26 & 22 & 16 \\
\hline Ética e Gestão & -- & -- & -- & -- & -- & -- & -- & 4 & 12 & 12 & 16 \\
\hline $\begin{array}{c}\text { Leitura e Ensino } \\
\text { da Bíblia }\end{array}$ & -- & -- & -- & -- & -- & -- & -- & 11 & 15 & 7 & 10 \\
\hline Liturgia & 11 & -- & 4 & 5 & -- & -- & -- & -- & -- & -- & -- \\
\hline $\begin{array}{c}\text { Dimensões } \\
\text { do Cuidado e } \\
\text { Práticas Sociais }\end{array}$ & -- & -- & -- & -- & -- & -- & 2 & 6 & 1 & 3 & 2 \\
\hline $\begin{array}{c}\text { Aconselhamento } \\
\text { Pastoral }\end{array}$ & -- & -- & -- & -- & -- & -- & 3 & 5 & 2 & 5 & -- \\
\hline $\begin{array}{c}\text { HIV/AIDS e } \\
\text { Teologia }\end{array}$ & -- & -- & -- & -- & -- & -- & -- & -- & -- & 5 & 5 \\
\hline $\begin{array}{c}\text { Total de } \\
\text { Trabalhos Finais }\end{array}$ & 11 & 0 & 4 & 6 & 21 & 9 & 35 & 45 & 56 & 54 & 46 \\
\hline
\end{tabular}

Ao categorizar e analisar os resumos e as palavras-chave dos trabalhos finais do Mestrado Profissional em Teologia da Faculdades EST nos anos de 2003 a 2013, verificou-se uma grande variedade de assuntos pesquisados, o que muitas vezes dificultou a categorização. Essa constatação pode ser percebida especialmente nas linhas de pesquisa de aconselhamento pastoral, dimensões do cuidado e práticas sociais, e HIV/AIDS e teologia. Na linha de pesquisa aconselhamento pastoral, foram arroladas 41 palavras-chave, sendo que dessas somente três se repetem: família (3 vezes), espiritualidade ( 2 vezes), mulher ( 2 vezes). Na linha dimensões do cuidado e práticas sociais são trazidas 31 palavras-chave, das quais se repetem somente duas: IECLB (2

11 Em 2004, não houve trabalhos finais concluídos, tendo em vista que a primeira turma de liturgia finalizou em 2003 e o segundo grupo iniciou em 2004. 
vezes) e sociedade (2 vezes). Na linha HIV/AIDS e teologia há 11 palavras-chave, sem que nenhuma se repita nos resumos dos trabalhos finais. ${ }^{12}$

$\mathrm{Na}$ linha de pesquisa liturgia, os assuntos podem ser agrupados nas seguintes categorias: ofícios (Santa Ceia, Batismo); liturgias (de diversas denominações religiosas, como anglicana, luterana, reformada); culto (terapêutico, cristão); diversos (infância, laicato, audição, comunicação, música, clero, negritude, calendário litúrgico).

$\mathrm{Na}$ linha de pesquisa educação comunitária com infância e juventude, as temáticas mais pesquisadas foram escola, educação, formação docente, gestão democrática, leitura; e outros assuntos relacionados com educação e com a proposta da linha de pesquisa, como infância, juventude, direitos humanos, cidadania, espiritualidade, desenvolvimento humano, mídia, projetos sociais.

$\mathrm{Na}$ linha de pesquisa de ética e gestão, os assuntos que mais foram pesquisados são educação/escola/ensino, políticas públicas, cuidado, espiritualidade, religião/ religiosidade, sustentabilidade/meio ambiente, ética e moral, mídia, cidadania/direitos humanos, povos indígenas, gestão (neste caso, de valores, de pessoal e empresarial).

$\mathrm{Na}$ linha de pesquisa ensino e leitura da Bíblia, os assuntos mais pesquisados são Bíblia (Novo Testamento, Antigo Testamento, leitura popular da Bíblia, Provérbios, evangelhos sinóticos); hermenêutica (de gênero e contemporâneas), literatura joanina, antropologia, religião/religiosidade. ${ }^{13}$

\section{Pesquisa com egressos e egressas do Mestrado Profissional}

A pesquisa social ${ }^{14}$ com egressos e egressas foi realizada por meio eletrônico. Foi enviada uma mensagem para um público de 378 pessoas, que foram convidadas a participar da pesquisa e receberam explicações sobre como essa seria realizada. O questionário com 14 perguntas e o Termo de Consentimento Livre e Esclarecido foram anexados à mensagem, com o pedido de que o Termo de Consentimento Livre e Esclarecido fosse lido e, estando de acordo com os termos da pesquisa, fosse dado prosseguimento, respondendo ao questionário que deveria ser devolvido. O projeto de pesquisa foi cadastrado na Plataforma Brasil e aprovado pelo Comitê de Ética em Pesquisa da Faculdades EST em 2015.

O questionário teve como objetivo verificar quais foram as mudanças que podem ser percebidas pelos egressos e egressas na sua atuação profissional e no seu contexto após o término do Mestrado.

Ao todo foram respondidos 43 questionários. Constata-se que 22 são do sexo masculino $(51,2 \%)$ e 21 do sexo feminino $(48,8 \%)$. As faixas etárias de quem respondeu o questionário são bastante diversas, desde 31 anos até 70 anos. Na questão da procedência, percebe-se que 16 estados brasileiros estão representados, sendo o maior

${ }_{12}$ Relatório de Pesquisa apresentado ao Conselho de Pesquisa da Faculdades EST, em 2016.

${ }_{13}$ Relatório de Pesquisa apresentado ao Conselho de Pesquisa da Faculdades EST, em 2016.

14 Todos os dados apresentados constam no Relatório de Pesquisa apresentado ao Conselho de Pesquisa da Faculdades EST, em 2016. 
número oriundo dos estados da Bahia (5), Ceará (5), Rio Grande do Sul (5) e Distrito Federal (4). Dos 43 questionários respondidos, sete mestres/as afirmam que não trabalham na cidade onde moram; 11 mudaram de local de trabalho depois de terem concluído o Mestrado Profissional. Em termos de locais de trabalho, há um número significativo de mestres/as que trabalham no ensino superior, em universidades, faculdades e institutos federais. Outros/as trabalham em prefeituras e secretarias de educação.

Na questão das linhas de pesquisa, o maior número é da linha de pesquisa educação comunitária com infância e juventude (15), seguindo-se a de ética e gestão (14) e ensino e leitura da Bíblia e dimensões do cuidado (cada uma com 3). Em relação a esse dado, é relevante o fato de que a primeira linha de pesquisa está sendo oferecida desde 2005, tendo em 2017 a sua décima segunda turma. Em relação à segunda linha de pesquisa, essa tem, nos últimos anos, o maior número de discentes. Outras linhas de pesquisa que não estão sendo mais oferecidas também foram mencionadas, como aconselhamento pastoral, liturgia e HIV/AIDS e teologia.

Os motivos que levaram egressos e egressas a escolherem a Faculdades EST foram o fato de o curso ser oferecido na modalidade em módulos, com aulas sempre nos meses de janeiro e julho, num período de 21 dias letivos, que permite conciliar estudo e trabalho; o conceito da instituição em termos de organização, o conceito na CAPES, a qualificação do corpo docente. Também foi mencionado o ingresso na Faculdades EST por indicação de outros/as mestrandos/as que foram ou são discentes da instituição.

A maior contribuição que o Mestrado Profissional trouxe foi o aperfeiçoamento pessoal e profissional: "Contribuiu significantemente na vida pessoal e profissional concedendo maiores oportunidades e reconhecimento no campo acadêmico". Além disso, as contribuições referidas foram em termos de mudança e ampliação de visão de mundo, ampliação de referencial teórico, troca de conhecimentos e experiências entre discentes de outros contextos e o corpo docente da Faculdades EST. Também foi dada ênfase na mudança de visão sobre a teologia e no aperfeiçoamento da vida espiritual e ministerial. Destaque também foi dado à possibilidade de fazer pesquisa, às leituras e textos que foram elaborados no transcorrer do curso, além do reconhecimento acadêmico pelo fato de ser agora mestre/a. Essas constatações podem ser percebidas na seguinte resposta:

O MP contribuiu muito para uma melhor organização do meu saber, hoje consigo ter um olhar mais de pesquisador. Sendo assim, tenho maior segurança profissional na minha área de atuação. Sem dúvida melhorei muito a minha visão de mundo.

As maiores mudanças sentidas após a conclusão do Mestrado Profissional foram o aumento salarial e a consolidação da carreira profissional, a ampliação de atividades profissionais e convites para palestras, conferências e cursos de formação de docentes: "Melhor salário, melhor prática docente e mais opções de trabalho". Além disso, também foi citado que há maior prestígio profissional, a admiração e o respeito de colegas, maior penetração nos espaços acadêmicos e a possibilidade da docência 
no ensino superior; além disso, a melhora na autoestima, com uma atuação docente com maior conhecimento e segurança. Como afirma uma mestra:

O curso como um todo me transformou enquanto pessoa; hoje em tudo que faço me vejo desempenhando minhas atividades com mais zelo e presteza. Sinto-me uma cuidadora por excelência. A pesquisa atual e relevante me levou a apresentar em congressos e outros eventos de produção científica, por várias vezes. Promoção no plano de carreira.

Em termos de ganhos da instituição, egressos e egressas apontam para o fato de essa ter um/a profissional mais capacitado/a, com boa formação, mais crítico/a e atuante também nas questões sociais; um/a profissional mais competente, solidário/a e humano/a nos relacionamentos, tendo uma visão mais ampliada do mundo e dos conceitos; ter um/a profissional com uma ótica teológica diferenciada, mais comprometido/a com valores éticos e com responsabilidade social. A instituição ganha em termos de credibilidade pelo fato de ter um quadro docente mais qualificado com mestres/as e doutores/as, que se engajam com maior competência nas pesquisas, em projetos e nas orientações de pesquisa, tendo como resultado uma maior produção acadêmica.

Na resposta transcrita abaixo fica claro que a Faculdades EST, na sua organização acadêmica, foi modelo para uma melhoria na instituição em que o egresso atua profissionalmente.

Consegui escrever e entender a legislação pertinente ao ensino superior; entender e efetivar os princípios de ensino, pesquisa e extensão na instituição; graças à organização da EST consegui entender sobre os diversos programas e núcleos necessários na IES; os alunos entendem melhor a minha aula.

Uma das questões a que se propôs esta pesquisa foi verificar quais foram as transformações da realidade que a conclusão do curso trouxe para os contextos profissionais onde atuam mestres e mestras, egressos e egressas do Mestrado Profissional da Faculdades EST. As respostas acima, assim como também as demais que constam no relatório da pesquisa, e foram sistematizadas e apresentadas, respondem afirmativamente a essa pergunta e validam a hipótese da pesquisa, como consta no projeto de pesquisa: "A conclusão do curso traz um impacto social relevante para o meio e para o contexto profissional no qual o/a egresso/a atua, assim como também para sua carreira profissional em termos de avanços no seu plano de carreira". Essa constatação pode ser observada numa das respostas:

O MP/EST significou muito mais do que a conquista de uma titulação. Significou uma mudança de visão socioeducativa como também de prática profissional e social. Pois o MP/EST amplia nossas possibilidades de aprender e compreender o mundo em que vivemos, estimulando-nos a transformar nosso contexto. 
Nessa afirmação fica evidente que houve um impacto social em termos de mudanças e de transformação no contexto do egresso e egressa. Além disso, atende ao que está proposto na portaria $\mathrm{n}^{\circ} 17$ : "II - transferir conhecimento para a sociedade, atendendo demandas específicas e de arranjos produtivos com vistas ao desenvolvimento nacional, regional ou local". Assim afirma uma mestra: "Todos os conhecimentos que aprendi foram devolvidos para a instituição inclusive as escolas que pesquisei, procurei dar uma atenção maior para a formação dos seus professores".

\section{Considerações finais}

Ao categorizar e analisar os trabalhos finais do Mestrado Profissional em Teologia da Faculdades EST, nos anos de 2003 a 2013, verificou-se uma grande variedade de assuntos pesquisados, o que demonstra a amplidão das pesquisas realizadas pelos/as mestrandos/as do Mestrado Profissional. Se, por um lado, os assuntos são bastante variados e mostram a riqueza e a diversidade da pesquisa realizada no Mestrado Profissional, por outro lado, constata-se a relevância desses para quem vem de lugares e contextos tão diferenciados, como é o caso daqueles que compõem o corpo discente do Mestrado Profissional. Na pesquisa social é possível perceber que se, por um lado, 28 pessoas responderam que trabalham no ensino ou em secretarias de educação, por outro lado, há um grande número de trabalhos finais que pesquisam temas relacionados com sua inserção profissional, no caso, na educação.

Além disso, percebe-se também uma interdisciplinaridade dos assuntos, como, por exemplo, o assunto é da área bíblica, mas envolve também a educação. Nesse caso, percebe-se a adequação dos projetos de pesquisa aos objetivos da linha de pesquisa, ou seja, ensino e leitura da Bíblia. Há assuntos que poderiam estar mais vinculados a uma linha, mas são pesquisados em outra, como, por exemplo, gestão de pessoas sendo estudado na linha de ensino e leitura da Bíblia, ou então missio Dei na linha de ética e gestão.

Duas categorias estão presentes em diversas linhas de pesquisa: educação e religião/religiosidade. Esses dados mostram que mestrandos e mestrandas das diversas linhas e com formação nas mais diferentes áreas do conhecimento têm em comum o interesse na docência, seja na educação básica ou superior, e também na teológica. Uma segunda constatação: como o mestrado é em teologia, há um interesse e uma busca por diálogo com a religiosidade e a espiritualidade e com assuntos teológicos, mesmo que o foco de pesquisa seja outro.

A realidade, como demonstrada pela pesquisa, tanto pela multiplicidade de áreas de formação de pessoas que procuram o Mestrado Profissional da Faculdades EST como pela diversidade de temas que pesquisam fazendo interfaces com a teologia, remete às possibilidades de diálogo desta com outras áreas de conhecimento, como a educação, a psicologia, a sociologia, a antropologia. Inácio Neutzling, entre outros questionamentos, pergunta sobre o lugar da teologia na universidade nos dias de hoje e responde a essas questões a partir do conceito de "teologia pública", como uma possibilidade significativa em termos de diálogo da teologia com outras áreas de 
conhecimento e com a sociedade, buscando por respostas que visam à transformação da realidade. ${ }^{15}$

Neutzling parte da afirmação de Moltmann de que Deus é o problema da teologia e por isso ela "[...] é sempre teologia do reino de Deus [...]". Essa teologia do reino é pública, ou seja, "um discurso público em favor do evangelho público do reino de Deus"16. E nesse sentido está imbricada na realidade social, política, econômica, cultural e ecológica da sociedade, e contribui para a reflexão acerca das questões vitais e em todas as suas dimensões. A teologia não está vinculada somente à comunidade cristã ou a denominações religiosas, mas insere-se no espaço público com sua voz crítica e profética, buscando trazer a justiça de Deus e o zelo pela vida de toda a criação. Neutzling conclui:

A teologia deve, urgentemente, superar o restrito espaço das comunidades de fé, o espaço privado da comunidade eclesial, para interessar-se pelo bem comum da sociedade inteira, da humanidade inteira com todas as desesperanças, visto que também as comunidades particulares participam do bem comum e contribuem para o "bem viver" da sociedade. E o bem comum formula-se no confronto do espaço público ${ }^{17}$.

Assim as indagações e as perguntas que surgem a partir dos mais diferentes contextos de vida, seja a escola, a comunidade religiosa, as instituições de ensino, as vivências do cotidiano e que se transformam em perguntas de pesquisa, recebem respostas da teologia em diálogo com outras áreas do conhecimento nas pesquisas realizadas no Mestrado Profissional em Teologia da Faculdades EST.

O diálogo da teologia com outras áreas de conhecimento oferece a possibilidade de pensar a construção dos saberes e a pesquisa no Mestrado Profissional da Faculdades EST em termos de interdisciplinaridade. Para Edgar Morin, a interdisciplinaridade pode significar simplesmente uma justaposição de diferentes disciplinas ou "[...] pode significar também troca e cooperação [...]"18.

Outro conceito que parece adequado como forma de descrever esse diálogo entre saberes diz respeito à multidisciplinaridade. Para Morin, esse conceito é definido da seguinte maneira: "A multidisciplinaridade constitui uma associação de disciplinas, por conta de um projeto ou de um objeto que lhes sejam comuns; as disciplinas ora são convocadas como técnicos especializados para resolver tal ou qual problema; ora, ao contrário, estão em completa interação para conceber esse objeto e esse projeto [... $]^{\prime \prime 1}$. Já a transdisciplinaridade é a possibilidade "[...] de esquemas cognitivos que podem atravessar as disciplinas". Para Morin, em todos esses conceitos, uma questão é central,

\footnotetext{
15 NEUTZLING, Inácio. Ciência e teologia na universidade do século XX. Possibilidades de uma teologia pública; algumas abordagens. In: CAVALCANTE, Ronaldo; SINNER, Rudolf von (Orgs.). Teologia pública em debate. São Leopoldo: Sinodal; EST, 2011. p. 176-177.

16 NEUTZLING, 2011, p. 177.

17 NEUTZLING, 2011, p. 180.

18 MORIN, Edgar. A cabeça bem-feita: repensar a reforma, reformar o pensamento. Tradução Eloá Jacobina. 8. ed. Rio de Janeiro: Bertrand Brasil, 2003. p. 115.

19 MORIN, 2003, p. 115.
} 
que nomeia de "noções-chave" e perpassam as definições de cada um: "[...] cooperação; melhor, objeto comum; e, melhor ainda, projeto comum" ${ }^{20}$. Isso não significa uma relativização, no sentido de que as diferentes disciplinas e suas áreas de conhecimento perdem suas características específicas. Elas permanecem, ainda que estejam em diálogo: "Não se pode demolir o que as disciplinas criaram; não se pode romper todo o fechamento: há o problema da disciplina, o problema da ciência, bem como o problema da vida; é preciso que uma disciplina seja, ao mesmo tempo, aberta e fechada"21.

Amparado nesses conceitos de interdisciplinaridade, multidisciplinaridade e transdisciplinaridade, é possível ampliar os horizontes do conhecimento e estabelecer as relações possíveis, buscando respostas para as indagações que a vida e os contextos fazem aos mestrandos e mestrandas. Pesquisar assuntos como educação e espiritualidade, gestão de pessoas e ética do cuidado, Bíblia e ensino coloca saberes em diálogo e possibilita a cooperação visando ao bem comum, como afirma a teologia do reino de Deus e por isso pública, porque comprometida com as pessoas e com a vida. Egressos e egressas, quando falam de suas percepções após o término de seu curso, apontam para mudanças e transformações pessoais e profissionais, também na sua forma de ver a teologia e sua própria espiritualidade.

Outro dado da pesquisa social que merece uma reflexão é o número de 43 questionários respondidos num universo de 387 egressos e egressas. Assim os resultados aqui apresentados refletem as opiniões e as vivências e experiências profissionais, após o término do curso, desse público.

Uma questão a ser considerada é o fato de que não há um acompanhamento sistemático a egressos e egressas realizado pela instituição. Esse é um desafio que se apresenta e poderá ser implementado nos próximos anos.

\section{Referências}

ATAS do Conselho de Pós-graduação e Pesquisa da Faculdades EST. BARDIN, Laurence. Análise de Conteúdo. Lisboa: Edições 70, 2002.

MESTRADO Profissional em Teologia. Documentação acadêmica. Guia Acadêmico. Disponível em <http://www.est.edu.br/pos-graduacao/mestrado-profissional/documentacao-academica $>$. Acesso em: 11 abr. 2016.

MESTRADO Profissional: Disponível em: $<$ http://www.capes.gov.br/avaliacao/sobre-a-avaliacao/mestrado-profissional-o-que-e>. Acesso em: 11 abr. 2016

MORIN, Edgar. A cabeça bem-feita: repensar a reforma, reformar o pensamento. Tradução Eloá Jacobina. 8. ed. Rio de Janeiro: Bertrand Brasil, 2003.

NEUTZLING, Inácio. Ciência e teologia na universidade do século XX. Possibilidades de uma teologia pública; algumas abordagens. In: CAVALCANTE, Ronaldo; SINNER, Rudolf von (Orgs.). Teologia pública em debate. São Leopoldo: Sinodal; EST, 2011.

PORTARIA Normativa $\mathrm{n}^{\circ}$ 17, de 28 de dezembro de 2009. Disponível em: <www.capes.org. br>. Acesso em: 12 abr. 2016.

RELATÓRIO de Pesquisa apresentado ao Conselho de Pesquisa da Faculdades EST, em 2016.

${ }^{20}$ MORIN, 2003, p. 115.

${ }^{21}$ MORIN, 2003, p. 115. 